\title{
A CONTRIBUIÇÃO DO PERITO CONTÁBIL NO JUDICIÁRIO: TECNOLOGIA COMO FERRAMENTA DE APOIO
}

\section{ARTIGO ORIGINAL}

LEITE, Yasmin Marreira ${ }^{1}$

LEITE, Yasmin Marreira. A contribuição do Perito Contábil no Judiciário: Tecnologia como ferramenta de apoio. Revista Científica Multidisciplinar Núcleo do Conhecimento. Ano 05, Ed. 03, Vol. 12, pp. 05-15. Março de 2020. ISSN: 2448-0959, Link de acesso: https://www.nucleodoconhecimento.com.br/contabilidade/tecnologiacomo-ferramenta

\section{RESUMO}

A perícia contábil é realizada por profissionais altamente qualificados, especializados, os quais detêm profundo conhecimento e experiência na área, aplicando suas habilidades para evidenciar determinado fato ou ato. O objetivo deste trabalho é salientar a importância do profissional contábil na comprovação das informações contidas em processos judiciais e como sua fundamentação, através de laudos técnicos, auxiliam o magistrado na tomada de decisões e assim como ressaltar a contribuição e notoriedade da tecnologia como ferramenta auxiliadora do trabalho. Considerando o volume de informações a serem analisadas pelos peritos contábeis, a tecnologia é uma grande aliada para garantir a acurácia das informações que são, inclusive, disponibilizadas às autoridades fiscais, possibilitando maior volume de análises em tempo hábil, quando necessário, permitindo agilidade na conclusão do laudo e, consequentemente, do processo. A perícia será de natureza contábil quando sua análise retratar dados sobre o patrimônio de qualquer entidade. Sua execução é realizada pelo perito contábil que através de técnicas como: exame; vistoria;

\footnotetext{
${ }^{1}$ Pós - Graduada em Perícia e Auditoria Contábil, Pós - Graduada Gestão Tributária e Bacharel em Ciências Contábeis.
} 
indagação; investigação; arbitramento; mensuração; avaliação; respaldam a autenticidade e veracidade das informações compreendidas no processo judicial. Os resultados adquiridos no estudo apontam alguns predicativos que precisam ser assegurados pelos peritos para realização das análises: concordância; assiduidade; credibilidade; domínio da matéria periciada; confirmando atributos primordiais para o exercício da profissão. O presente trabalho usou como material de apoio para o assunto apresentando: normas; legislações; resoluções e obra literária para embasamento no assunto exposto. Diante disto, pode-se concluir que é de extrema importância a figura do perito no assessoramento do magistrado quando se trata de processos que necessitem de análises da área contábil, assim como os ganhos advindos da tecnologia a favor da justiça, consequentemente, impactando de forma positiva o trabalho do perito.

Palavras-chave: Análises Contábeis, Perito Contábil, tecnologia, veracidade, Assessoramento Magistrado.

\section{INTRODUÇÃO}

Na elaboração do laudo cabe ao perito contábil contribuir com as partes interessadas sobre o assunto em análise, juiz poderá fazer ao perito perguntas pertinentes aos esclarecimentos de fatos. Cabe ao magistrado toda a verificação dos questionamentos expostos pelas partes e a recusa relacionado aos dados que não forem consideradas pertinentes.

Com o crescimento da área contábil na Europa, segundo Santos (1995), a perícia começou a ser utilizada como confirmação em discussões, fazendo assim o perito contador uma figura fundamental para ratificar a confiabilidade do parecer judicial.

No tocante a perícia contábil brasileira, o perito contador tem a função de explicar dúvidas do magistrado e das partes, sendo uma peça fundamental para legitimar a informação enviado ao Juiz. 
O Magistério carece de conhecimento técnico - científico para julgar casos que envolvam natureza contábil, desta forma, é solicitado o parecer do perito - contador com intuito de contribuir de forma técnica para sentença do Juiz.

O profissional habilitado para conduzir o trabalho da perícia contábil precisa ser bacharel em ciências contábeis e ser inscrito no conselho de contabilidade da sua região. O bacharelado precisa elaborar um relatório bem fundamentado e sucinto, com o objetivo de auxiliar, de maneira imparcial, a sentença do magistrado.

O contador deverá ser justo, ético, imparcial, especializado para apresentar o parecer. De acordo com o $\S 3^{\circ}$, artigo 473 do Código de Processo Civil (2015), para o desempenho da função, o profissional poderá utilizar de todos os meios pertinentes, escutando testemunhas, reunindo informações, buscando documentos que estejam em poder de terceiros e departamento público, assim como preparando o laudo com ilustrações, fotografias, e outros documentos importantes para seu parecer.

Com o passar dos anos, a área contábil tem se transformado, não apenas nas normas e regulamentações, mas sim nas práticas. O crescimento resulta da necessidade do mercado em receber informações cada vez mais aprofundadas e rápidas para tomada de decisões seja ela financeira, gerencial ou administrativa.

Assim como a ciência constantemente vem evoluindo, o profissional precisa acompanhar essa evolução a fim de aprender conceitos e instrumentos novos que estão sendo utilizados no mercado. Atualmente, um dos instrumentos mais relevantes é a tecnologia que tem por objetivo otimizar o trabalho de forma ágil e prática. A utilização de soluções tecnológicas nas empresas, diminui consideravelmente o risco iminente da perda de documentos por má conservação ou qualquer outro motivo, uma vez que essa permite que os documentos sejam armazenados em diversas fontes de dados, inclusive em "nuvem", garantindo, assim, que quaisquer falhas no processo não ensejem na perda total das informações.

$\mathrm{Na}$ atualidade, o crescimento tecnológico na área contábil tem sido acelerado pelas diversidades de ferramenta que estão sendo inseridas no mercado. Isto, aliado à 
propagação da tecnologia da informação por todas as atividades das companhias, vêm obrigando a necessidade de refletir sobre os efeitos provocados pelo avanços tecnológicos na atividade contábil.

O Trabalho apresentado busca evidenciar a contribuição do perito contador nas decisões judiciais, através do assessoramento ao magistrado, e o dinamismo da tecnologia apoiando o desempenho da perícia.

\section{PERÍCIA NA ÁREA CONTÁBIL}

Antes de se discutir sobre a perícia na área contábil é necessário compreender o que é a informação contábil e a sua relação com a perícia. Conforme Bertuchi (2019), a informação contábil visa, sobretudo, demonstrar a viabilidade econômico-financeira de uma empresa em processo de recuperação bem como aponta as estratégias, e, ainda, os meios a serem utilizados nesse processo de recuperação. Assim sendo, em todos esses fatores, segundo o autor, percebe-se que a fonte da informação é a contabilidade da empresa devedora, visto que ela atua como a principal base que sustenta o pedido de recuperação judicial. Nesse sentido, a contabilidade é compreendida como uma das protagonistas nos processos que englobam a recuperação judicial. Bertuchi (2019) alude, também, que além do uso e da utilidade da informação contábil, a compreensão da sua ideia é de igual relevância, seja por parte da empresa solicitante da recuperação judicial quanto por parte do administrador judicial, dos credores e do juiz. Dentre esses agentes, destaca-se o administrador judicial em razão da sua atuação no processo de recuperação judicial.

De acordo com o estudo de Bertuchi (2019), a figura do administrador judicial compreende a necessidade de se pensar em um agente portador de um conhecimento multidisciplinar, e, dessa forma, ele deve ser capaz de avaliar a viabilidade da recuperação da empresa a partir da verificação de créditos, da fiscalização do processo de recuperação, da manifestação em relação aos procedimentos e decisões a serem tomados bem como precisa auxiliar o juiz, e, caso seja solicitado, deve substituir os administradores ou titulares da empresa em recuperação. Dessa forma, 
cabe, ao administrador judicial, que, por sua vez, deverá se basear em livros contábeis e nos demais documentos de caráter comercial e fiscal voltados ao devedor, realizar a verificação dos créditos, conforme o Art. 7 da Lei de № 11.101/2005. Verificada a conformidade, o profissional emite os editais aos credores.

Bertuchi (2019) elucida, ainda, que o administrador fiscal deverá fiscalizar todo o processo em andamento da recuperação judicial. O autor enfatiza, também, que parte do sucesso do processo da recuperação judicial se relaciona com a atuação do administrador judicial. Com a Lei de № 11.101/2005 foi incluída a figura do contador, e, assim, ele se encontra habilitado para atuar como administrador judicial. Porém, para Bertuchi (2019), a participação dos contadores como administradores judiciais, ainda hoje, é bastante restrita, uma vez que é frequente que esses desempenham a função de peritos contábeis neste tipo de processo, quando solicitado pelo juiz. Segundo Bertuchi (2019, p. 22) “o juiz solicita quando há indícios de elaboração de documentos contábeis não fidedignos, apresentando dados inexatos, simulados ou omissos, com o intuito de trazer benefícios à organização mesmo antes do pedido de RJ, constituindo-se práticas fraudulentas".

A perícia é o instrumento que dispõe-se a produzir componentes comprobatórios que sejam utilizados como evidências em vias judiciais ou extrajudiciais. Ainda segundo Sá (1996), a inovação da perícia fornece uma posição sobre a pesquisa feita do patrimônio, ora de empreendimento ora de indivíduos, cuja verificação, por natureza, é estabelecida ou requisitada pelo interessado. Podemos dizer que a perícia contábil analisa situações ligadas ao patrimônio, apresentando um ponto de vista para questão em discussão, segundo o autor Sá (1996) através de arbitramentos, vistorias, investigações, exames, indagações, avaliações, quaisquer métodos essenciais ao parecer. $O$ instrumento aqui analisado é entendido de uma forma ampla, como trabalho especializado com intuito da obtenção de comprovação e ideia a fim de direcionar uma autoridade na decisão de um fato ou enviar o confronto entre as partes.

Segundo Ornelas (1995), uma das categorias de prova pericial são as mostras técnicas à disposição, de uma maneira natural ou jurídica, contribuindo para evidência 
dos fatos contábeis. Segundo o autor Neves (2004) o arbitramento, exame, vistoria, investigação, indagação que fundamentam os aspectos técnicos da contabilidade, evidenciam as provas que vão contribuir na formação da convicção do Juiz, através da perícia judicial. O conceito da perícia contábil segundo a Norma Brasileira de Contabilidade NBC - TP 01 (2009) nos diz que é um conjunto técnico e científico de procedimentos que auxiliam o profissional na elaboração do laudo pericial - contábil para fundamentação dos elementos de prova destinadas a instância decisória. Os fatos alterados no patrimônio de uma entidade segundo Magalhães Et Al (2006) é um trabalho de análise e verificação por parte do profissional de Ciências Contábeis, que tem o papel de esclarecer ao Juiz ou Administrador Judicial os fatos modificadores. Podemos dizer que a Perícia Contábil tem a necessidade de um especialista técnico, contador, que irá fundamentar esclarecer e posicionar através do parecer sobre o quesito em questão de forma a esclarecer o magistrado a eventual dúvida.

\subsection{OBJETO DA PERÍCIA CONTÁBIL}

A perícia contábil não deverá extrapolar a análise solicitada pelo Juiz, devendo o contador ater-se aos pontos solicitados.

O objetivo principal da perícia de acordo com As Normas Brasileiras de Contabilidade NBC T13 - Da perícia contábil - (2009) é conduzir a competência decisória a fim de atestar a veracidade do fato em questão, assim como demonstrar, através de provas, o parecer da conclusão.

Tem como propósito respaldar as informações solicitadas, mostrando a autenticidade dos fatos de maneira imparcial e digna de fé de forma: objetiva; fidedigna; clara; confiável; precisão e clareza. 


\subsection{AGENTES DA PERÍCIA CONTÁBIL}

\section{$2.3 \mathrm{JUIZ}$}

É autoridade pública, competente a julgar por meios de provas seguindo o princípio jurídico e senso de justiça; assisado por direcionar e decidir o processo, investido legalmente com poder para o exercício da atividade jurisdicional.

Conforme o art. 93,I, da Constituição Federal, o cargo ocupado pelo juiz dar-se-á mediante a concurso público, com a presença da Ordem dos Advogados do Brasil em todas as etapas, que exige do bacharel em direito, no mínimo, três anos de experiência na área jurídica e mantendo-se, nas nomeações, à ordem de classificações.

O Juiz de maneira nenhuma poderá tomar decisões através de convicções pessoais sem embasamento técnico, as decisões serão tomadas baseadas em provas dos laudos, como exemplo, a pericial contábil.

\subsection{PERITO CONTADOR}

Consoante com as Normas Brasileiras de Contabilidade Resolução NBC P2 (2005), é o profissional graduado, rotulado com o contador registrado no Conselho Regional de Contabilidade, que executa atividade pericial de maneira pessoal, sendo especializado e altamente qualificado para apreciação da matéria. O contador deverá possuir experiência e conhecimento sobre o assunto periciado, sempre observando o código de ética profissional do CFC.

O mesmo precisa se manter atualizado de maneira que possa aplicar seus conhecimentos fidedignamente.

Ao atuar em processos judiciais, o perito deverá ser intimado, por meio eletrônico, para execução de suas atividades, com no mínimo 10 dias de antecedência, conforme estabelece o Art. 477, § 4º, da Lei ㄲo 13.105/2015 (Código de Processo Civil) 
A NBC TP 01 (2015) estabelece que o perito deve estar atento ao escopo de suas análises, tanto em relação ao objeto quanto ao período compreendido para execução da perícia contábil. Adicionalmente, é necessário que o perito do juízo informe às partes a data e local de início da realização da perícia contábil.

Neste sentido, quando a perícia estiver relacionada à questão judicial, o perito pode, eventualmente, vir a recusar o atendimento a diligências ou informar qualquer dificuldade na realização da perícia, a qual deverá ser comunicada, com as respectivas justificativas e comprovações ao magistrado que inviabilizem seus trabalhos. Em caso de perícia extrajudicial, qualquer inviabilidade deverá ser comunicada à parte contratante.

\subsection{LAUDO PERICIAL}

Estabelece prova técnica cujo perito expõe suas análises, pesquisas e resultados. Segundo Mello, Paulo (2013) o laudo pericial para ser completo precisa conter: Abertura, Introdução, Desenvolvimento, Quesitos e Respostas, Conclusão Técnica, Encerramento, Anexos e Documentos.

A Perícia deve deliberar o objeto e estabelecer o objetivo do seu trabalho, e reconhecer os dados essenciais a seu desenvolvimento, apurar a necessidade ou não de novas informações, que podem ser alcançadas por meio de investigações, validar as informações examinadas, confrontar dados, entre outros atos, todos sucedidos de forma técnica e imparcial.

Ante o exposto, pode-se concluir que a elaboração do laudo pericial, o qual conterá o detalhamento das análises técnicas referentes aos pontos a serem esclarecidos no processo, assim como as devidas validações das informações, será fundamental para o desfecho do processo e tem por finalidade auxiliar o juiz na conclusão do julgamento. 


\section{O IMPACTO DA TECNOLOGIA NO TRABALHO PERICIAL}

Nos dias atuais, a evolução tecnológica vem sendo marcada pela aceleração e pela variedade de novas ferramentas que estão sendo inseridas no mercado, com o objetivo de otimizar processos e tarefas manuais, possibilitando mais tempo dispendido em análises e atividade que gerem maior valor agregado.

Tais fatores vêm estabelecendo a necessidade de refletir sobre os impactos gerados na atividade contábil. O profissional da área contábil precisa estar atento às mudanças na legislação e também nas transformações que a tecnologia oferece, pois ela adentra todas as atividades econômicas, até mesmo na atuação como perito contábil.

De acordo com IPOG, um dos grandes desenvolvimentos da perícia contábil durante a operação Lava Jato foi assegurado pela implantação de software, tais como, o My Webday e o Draisys, que auxiliaram o perito contador na investigação e identificação das fraudes e outras informações necessárias.

Um dos exemplos atuais que está presente nas atividades do profissional contábil é o preenchimento, validação e transmissão de arquivos digitais enviados para as autoridades fiscais no SPED (sistema público de escrituração digital), que é um relevante progresso no sistema de integração de troca de informação entre o contribuinte, autoridades fiscais e IPED. Trata-se de processador de evidências digitais, a fim de substituir documentos que seriam disponibilizados fisicamente.

A remodelação digital, principalmente no campo pericial contábil apresenta uma evolução do trabalho já que a tecnologia reuniu ferramentas novas que aperfeiçoam o ofício promovendo velocidade das informações de forma ágil e segura. Podemos concluir que a tecnologia e atuação do profissional contábil estão ligadas e representam um forte resultado em nossa comunidade social, pois falhas humanas são diminuídas, visto que a tecnologia oferece essa condição, o que tornou mais difíceis problemas com perdas, omissão e alterações de informações a serem disponibilizadas para o perito. 


\subsection{AS VANTAGENS DA TECNOLOGIA NO CAMPO DA JUSTIÇA}

Qual foi a vantagem da informatização no auxílio da perícia contábil?

É possível utilizar a internet como ponte para comunicação e disponibilização de laudos e pareceres com rapidez e prontidão de acesso, o que garante sigilo na passagem e no armazenamento das informações. Outras vantagens observadas na pesquisa é o protocolo on-line de petições e a diminuição dos extravios de cartório. A assinatura digital é um meio seguro que garante a veracidade dos documentos eletrônicos e a confirmação do autor da transmissão das informações às autoridades fiscais ou não fiscais.

A medida provisória $n^{0}$ 2.200-2/01 certificou a validade jurídica de documentos eletrônicos e o uso de certificados digitais para garantir a autenticidade dos mesmos.

Ademais, no que refere-se aos processos judiciais, podemos citar a Lei oํ 11.419 de 2006, que dispõe a informatização do processo judicial, desde 2007, a qual se aplica a processos civil, penal e trabalhista, compreendendo, também, juizados especiais, de forma a trazer maior celeridade e ganhos aos magistrados e para as partes envolvidas no processo.

O perito do juiz e seus assistentes hoje usam os certificados digitais na tramitação por meios eletrônicos de documentos oficiais, que já são informatizados ao juiz e suas partes. A artificação digital e laudos periciais diminuem custos, guardam dados dos laudos, criam um novo meio de armazenamento para sigilo das informações e ganham velocidade no parecer dos autos, pois facilita ao assistente técnico, advogados e juiz o recebimento das informações em tempo real, o laudo, o que economiza tempo e dinheiro com a seguridade. Outro ponto interessante para se refletir são os estímulos de redução da poluição, a diminuição da circulação do fórum, a contenção de papéis e tintas, a diminuição dos espaços nos arquivos, e a importante dela a moldagem dos profissionais à nova eficiência a favor da justiça, o que nos dá transparência nos processos. 
Um dos grandes avanços que a tecnologia trouxe para justiça brasileira e, consequentemente, aos peritos que auxiliam nos processos judiciais, foi a diminuição do manuseio de papéis, pois na maioria dos fóruns, existe o acesso do processo através do sistema virtual que é mais célere, já que ficam à disposição dos juízes, peritos, dos assistentes e das partes.

\section{CONSIDERAÇÕES FINAIS}

A perícia contábil torna-se cada vez mais relevante em decorrência das constantes alterações nas práticas contábeis, as quais são acompanhadas pelas diversas mudanças globais. A contabilidade compreende estudo matemático, jurídico e de outras ciências, por isso, o perito contábil precisa dominar o exercício da profissão com muita competência e conhecimento.

Pode-se dizer que a perícia contábil tem seu papel fundamental para o auxílio na tomada de decisão do magistrado, servindo como instrumento na fundamentação do processo e tornando-se essencial para aplicação justa da lei.

O profissional deve seguir as disposições dos princípios fundamentais da contabilidade, com intuito de aplicar as Normas Brasileiras de Contabilidade, as quais são obrigatórias e extensivas a todos os profissionais da área. Além disto, seguir as regras do Código de Ética Profissional do Contabilista, garante a fidedignidade do seu ofício.

É primordial para o trabalho pericial - contábil a educação continuada para sua melhor prática.

Neste contexto, o meio digital é excelente e inovador, de suma importância na existência da justiça; sem dúvida a artificação digital de forma conjunta com a perícia tem muito a contribuir com a mobilidade jurídica e qualidade no trabalho exercido pelo perito, pois veio para somar na agilidade dos processos da justiça e aos peritos no levantamento das suas fundamentações, permitindo-os análises mais detalhadas em um menor lapso temporal. 
Portanto, o Laudo Pericial, peça elucidativa, confeccionada por profissional capacitado, dotado de ética e reconhecido saber técnico científico, é um meio de prova que contribui para a certeza jurídica, sendo esta decisiva para tomada de decisões dos magistrados.

\section{REFERÊNCIAS}

BERTUCHI, F. I. Custos de transação e informação contábil na recuperação judicial de micro e pequenas empresas. 2019. 75 f. Dissertação (Mestrado em Ciências Contábeis) - Universidade Estadual de Maringá, Maringá, 2019.

BRASIL. Lei no 13.105, de 16 de março de 2015. Código de Processo Civil - CPC. Disponível em: http://www.planalto.gov.br/ccivil_03/_ato20152018/2015/lei/13105.htm\#art1045 Acesso em: 21/01/2018

BRASIL. Constituição (1988). Constituição da República Federativa do Brasil. Brasília, 1988. Disponível em: $<$ http://www.planalto.gov.br/ccivil_03/constituicao/constituicao.htm>. Acesso em 10/01/2020

BRASIL. MEDIDA PROVISÓRIA, de 24 de agosto de 2001. Institui a Infra-Estrutura de Chaves Públicas Brasileira - ICP-Brasil, transforma o Instituto Nacional de Tecnologia da Informação em autarquia, e dá outras providências. Disponível em: http://www.planalto.gov.br/ccivil_03/mpv/antigas_2001/2200-2.htm. Acesso em 16/02/2020.

BRASIL. Lei no 11.419, de 19 de dezembro de 2006. Dispõe sobre a informatização do processo judicial. Disponível em: http://www.planalto.gov.br/ccivil_03/_ato20042006/2006/lei//11419.htm. Acesso em 12/12/2019.

BLOG IPOG. A Perícia Contábil foi responsável por mais de 100 laudos produzidos e uma operação que impactou a política do país. Disponível em: 
https://blog.ipog.edu.br/contabilidade/pericia-contabil-operacao-lava-jato/. Acesso: 01/03/2020.

CONSELHO FEDERAL DE CONTABILIDADE.Resolução CFC ํㅗ 803, de 10 de outubro de 1996. Código de ética profissional do contador-CEPC. Disponível em http:// www.crcsp.org.br.Acesso em: 06/07/2018

- Resolução CFC 1.243, de 18 de dezembro de 2009 - Norma brasileira de contabilidade TP 01 - TP 13. Disponível em http:// www. cfc.org.br .Acesso em: 01/01/2019

. Resolução CFC 1056, de 25 de novembro de 2005 -Aprova a NBC P2.1Competência Profissional. Disponível em http:// www. cfc.org.br . Acesso em: 01/01/2018

MAGALHÃES, Antônio de Deus Farias et al. Perícia contábil:Uma Abordagem Teórica, Ética, Legal, Processual e Operacional - Casos Práticos. São Paulo: Atlas, 2006.

MELLO, Paulo Cordeiro. Perícia contábil. São Paulo: Senac, 2013, 25p.

NEVES, Antônio Gomes das. Curso Básico de Perícia Contábil. 2. Ed. São Paulo:Ltr 2004, 9p.

NORMA BRASILEIRA DE CONTABILIDADE, de 27 de fevereiro de 2015 - Aprova a NBC TP 01 - Perícia Contábil. Disponível em http:// www. cfc.org.br . Acesso em: $01 / 01 / 2018$

ORNELAS, Martinho Maurício Gomes de. Perícia Contábil. 2. Ed. São Paulo: Atlas, 1995.

SÁ, Antônio Lopes de. Perícia contábil. 2. Ed. São Paulo: Atlas, 1996. 
SANTOS, Moacyr Amaral. Prova judiciária no cível e comercial. 2 Ed. São Paulo: Max Limonad, 1955, 11p.

Enviado: Fevereiro, 2020.

Aprovado: Março, 2020. 